\title{
Face or Edge? Control of Molybdenite Surface Interactions with Divalent Cations
}

\section{Supporting Information}

Zhenzhen Lu, ${ }^{1}$ John Ralston, ${ }^{2}$ Qingxia Liu ${ }^{1 *}$

${ }^{1}$ Department of Chemical and Materials Engineering, University of Alberta, Edmonton, AB, T6G 1H9, Canada

2 Future Industries Institute, University of South Australia, Mawson Lakes, SA 5095, Australia

*Corresponding author: qingxia2@ualberta.ca, phone: 780-492-1119. 


\section{Image of $\mathrm{MoS}_{2}$ Face and Edge}
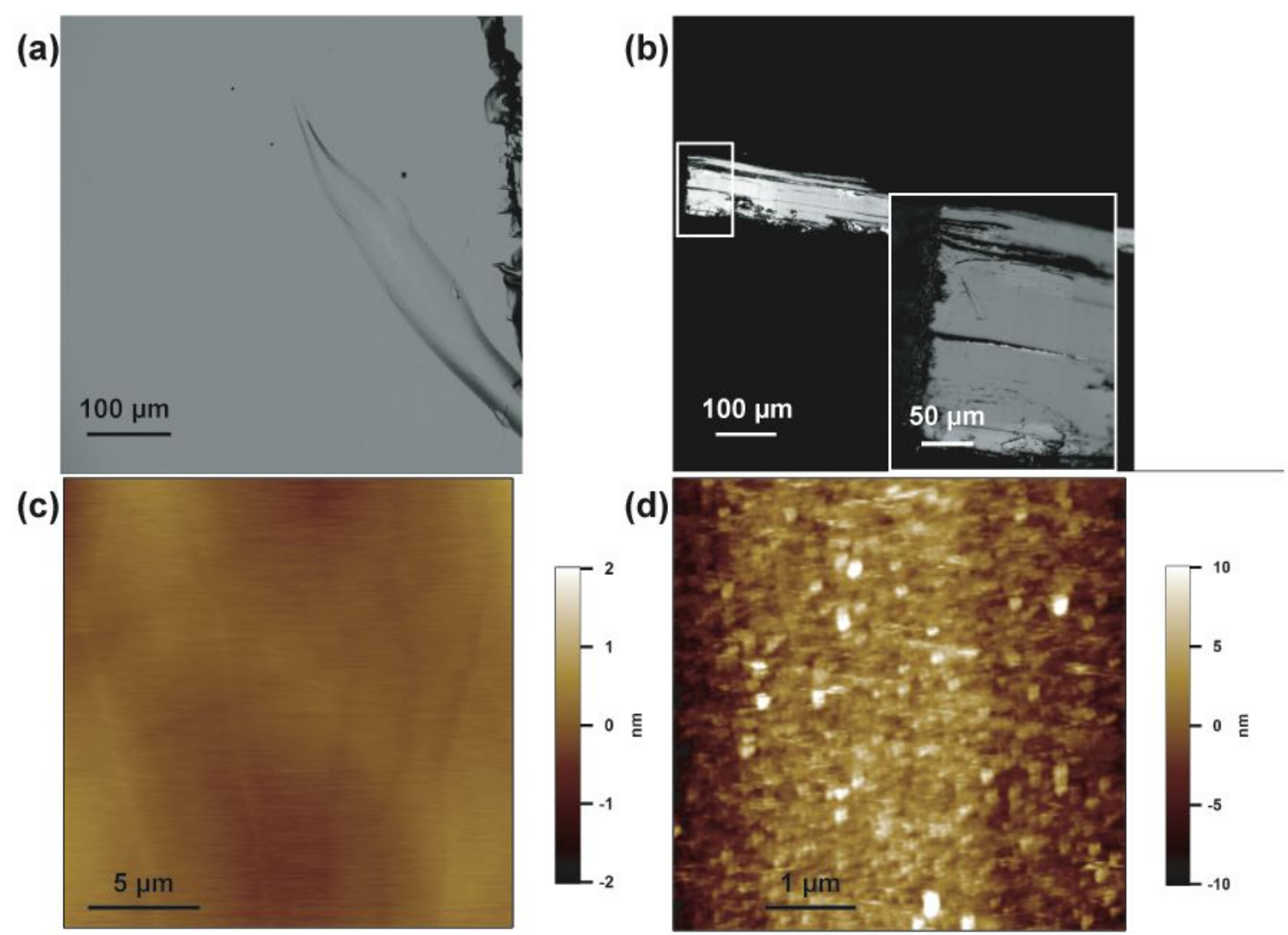

Figure S1. Optical and AFM height images of $\mathrm{MoS}_{2}$ face (a, c), and $\mathrm{MoS}_{2}$ edge (b, d). The inset in (b) shows zoom-in image of the area inside a white square. The root mean square roughness was measured at $0.2 \mathrm{~nm}$ on $\mathrm{MoS}_{2}$ face and $3.3 \mathrm{~nm}$ on $\mathrm{MoS}_{2}$ edge. Reprinted with permission from reference ${ }^{1}$. Copyright 2016 American Chemical Society.

\section{Determination of Surface Potential of AFM Tip in $10 \mathbf{~ m M ~ M g C l}$}

Zeta potentials were firstly determined for both silicon nitride and silicon dioxide (silica)

particles in $10 \mathrm{mM} \mathrm{MgCl}$ as a reference. In Figure $\mathrm{S} 2 \mathrm{~b}$, the zeta potentials of silicon nitride and silica are very close at $\mathrm{pH}$ 6-10. At $\mathrm{pH} 3$, the zeta potential of silicon nitride is $10.9 \mathrm{mV}$, while silica is negatively charged with a zeta potential of $-24.8 \mathrm{mV}$. The $\mathrm{pH}$ of Point of Zero Charge 
(pHpzc) of silicon nitride is determined at $\mathrm{pH} 4.4$ in $10 \mathrm{mM} \mathrm{MgCl}_{2}$, while the $\mathrm{pHpzc}$ of silica is not detected over $\mathrm{pH}$ range of 3-10, falling at lower $\mathrm{pH}^{2-3}$. Force measurements were conducted between the tip and the silicon wafer in $10 \mathrm{mM} \mathrm{MgCl}_{2}$ solution at $\mathrm{pH}$ values between 3-10. In Figure $\mathrm{S} 2 \mathrm{a}$, the interaction of tip and silica is attractive at $\mathrm{pH} 3$. As the $\mathrm{pH}$ rises, the interaction becomes repulsive. The interactions between the silicon nitride tip and silica are consistent with the trend of zeta potential. At $\mathrm{pH} 3$, the zeta potentials of silicon nitride and silica have opposite signs, which would result in an attractive EDL force. When the $\mathrm{pH}$ increases above 3, the zeta potentials of the two are both negative, which results in a repulsive EDL force. To further evaluate the surface potentials of both surfaces, experimental force curves were fitted using three models derived from DLVO theory. Before fitting, one point must be noted: when force curves are measured at different spots on the same surface, the contact area of the tip barely changes and it is only at the nanoscale (tip end radius $40-76 \mathrm{~nm}$ ) level, much smaller than the sample surface. Thus, the chance of any variation in surface potential of tip is much lower than that of sample surface, i.e. silica. The surface potential of the silicon nitride tip was fitted at a constant value for each $\mathrm{pH}$, while the surface potential of silica was averaged for five different spots. With this protocol in hand, the interaction between the silicon nitride tip and the silicon wafer during approach was fitted by DLVO theory.

In Figure S2a, all force curves between the silicon nitride tip and silica are fitted very well to a distance $<3 \mathrm{~nm}$ under constant charge and mixed model conditions. Surface potentials of silicon nitride tip and silica are resolved in $10 \mathrm{mM} \mathrm{MgCl}_{2}$. In Figure S2b, the fitted surface potential of silicon nitride matches with the zeta potential. For both techniques, the pHpzc of silicon nitride falls at $\mathrm{pH}$ 4.4. The surface potential of silicon nitride is slightly greater than its zeta potential, which suggests the surface potential may possibly be measured at a distance closer than the 
slipping plane (for zeta potential). For silica, the gradients of the fitted potential and zeta potential of silica are almost the same. Its surface potential is larger in magnitude than the zeta potential. Some deviation is observed at $\mathrm{pH}$ 10. Strong adhesion is also detected during retraction (pull-off) of the tip from the silica surface at $\mathrm{pH} 10$ (not shown here). These results could be attributed to $\mathrm{Mg}(\mathrm{OH})_{2}$ formation on the silica surface, discussed below. By DLVO force fitting, the surface potential of the silicon nitride tip is obtained at each $\mathrm{pH}$ for the $10 \mathrm{mM} \mathrm{MgCl} 2$ solution.

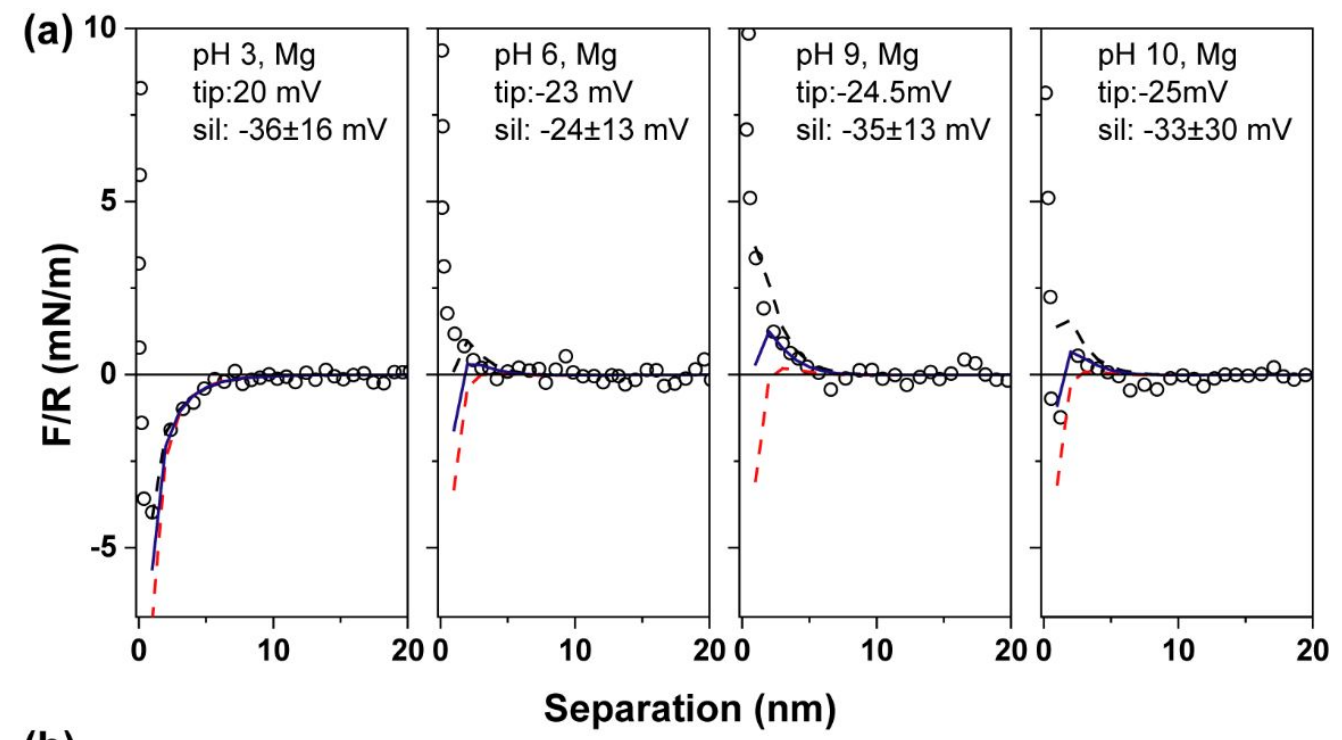

(b)

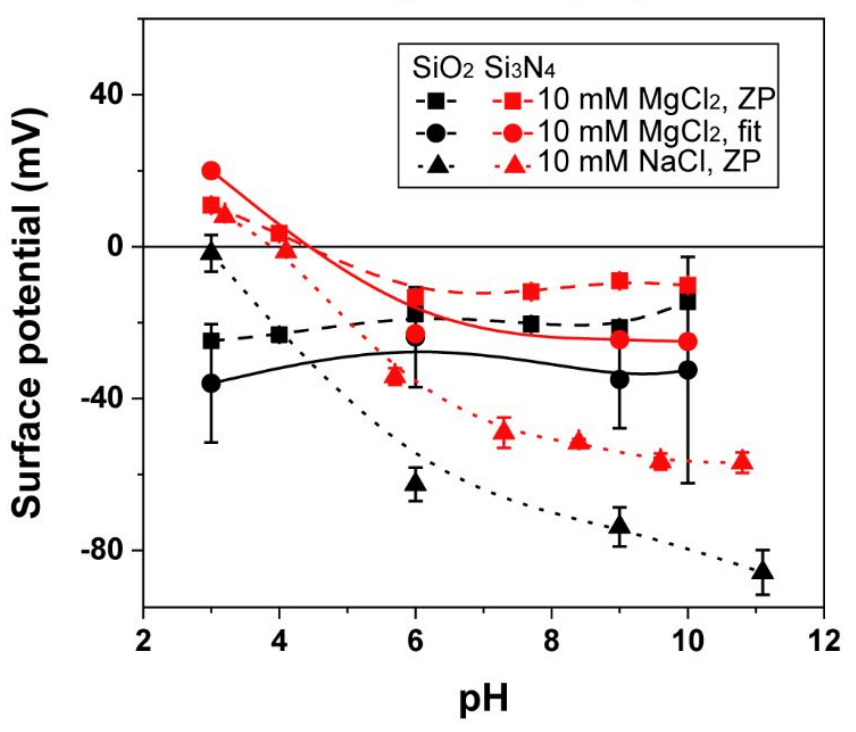


Figure S2. In $10 \mathrm{mM} \mathrm{MgCl}_{2}$, (a) force measurement between silicon nitride tip (tip) and silicon wafer (sil) and DLVO fitting. The symbols represent experimental force curves during approach. The dash and solid lines represent theoretical fittings under constant charge density (black dash), constant potential (red dash) and mixed (blue) boundary conditions. Hamaker constant $A$ is 2.43 $\times 10^{-20} \mathrm{~J}$ for silicon nitride /aqueous solution/silica system. (b) Surface potential of $\mathrm{SiO}_{2}$ and $\mathrm{Si}_{3} \mathrm{~N}_{4}$ by DLVO force fitting (fit) and zeta potentials (ZP) by electrophoretic measurement.

\section{Determination of Surface Potential of AFM Tip in $10 \mathbf{~ m M ~ C a C l}_{2}$}

The zeta potentials were firstly measured for both silicon nitride and silica particles in $10 \mathrm{mM}$ $\mathrm{CaCl}_{2}$ (Figure S3b). At pH 3, the zeta potential of silicon nitride is positive at $9 \mathrm{mV}$, while the zeta potential of silica is negative at $-24.4 \mathrm{mV}$. When the $\mathrm{pH}$ is above 6 , zeta potentials of both silicon nitride and silica stay negative and approach each other. The pHpzc of silicon nitride is detected at $\mathrm{pH} 4.7$, while the $\mathrm{pHpzc}$ of silica is not observed in the $\mathrm{pH}$ range of 3-11, falling at lower $\mathrm{pH}^{2-3}$.

Force measurements with the silicon nitride tip were conducted on a silicon wafer in $10 \mathrm{mM}$ $\mathrm{CaCl}_{2}$ solution. In Figure $\mathrm{S} 3 \mathrm{a}$, the interaction between the tip and silica is repulsive at $\mathrm{pH} 3$. As the $\mathrm{pH}$ increases to 6 , a weak attractive interaction is detected. At $\mathrm{pH} 7.7$, it changes to a repulsive interaction again. When the $\mathrm{pH}$ reaches 11 , very strong repulsive interaction is observed with the silica surface. To further evaluate the surface potentials of silicon nitride and silica, experimental force curves were fitted by DLVO theory. In Figure S3a, force curves in 10 $\mathrm{mM} \mathrm{CaCl} 2$ are well fitted by constant charge and mixed models. One exception is at $\mathrm{pH} 11$, where a repulsive 'bump' appears at distance $>13 \mathrm{~nm}$. This ‘bump' cannot be explained by 
classical DLVO forces. Despite this, the force data up to $10 \mathrm{~nm}$ were fitted by DLVO theory at $\mathrm{pH}$ 11. There is still an observable gap between force curve and the fitting, discussed below.

The surface potentials of silicon nitride and silica were obtained for $10 \mathrm{mM} \mathrm{CaCl}_{2}$ (Figure S3b). For silicon nitride, the surface potential matches with its zeta potential, having the same pHpzc of 4.7. However, the surface potential of silica shows an apparently different slope compared with the zeta potential data in $10 \mathrm{mM} \mathrm{CaCl}_{2}$. At $\mathrm{pH} 3-6$, the surface potential of silica is positive and decreases with increasing $\mathrm{pH}$. According to $\mathrm{Ca}^{\mathrm{II}}$ species distribution (Figure $5 \mathrm{~b}$ ), the $\mathrm{Ca}^{2+}$ cation is dominant at $\mathrm{pH} 3-6$. The positive value of surface potential may be attributed to $\mathrm{Ca}^{2+}$ adsorption on silica. As the $\mathrm{pH}$ rises to 7.7, the surface potential of silica becomes negative. At $\mathrm{pH} 11$, the strong negative surface potential is fitted from the strong repulsive force at distances $<10 \mathrm{~nm}$ shown in FigureS3a. To be noted, the trend of zeta potential of silica in $\mathrm{CaCl}_{2}$ solution reverses to rising as $\mathrm{pH}$ increasing, whilst it declines in $\mathrm{NaCl}$ solution. It suggests $\mathrm{Ca}^{\mathrm{II}}$ adsorption is evident on silica surface. At $\mathrm{pH} 11$, more $\mathrm{Ca}(\mathrm{OH})^{+}$presents in the solution (Figure $5 \mathrm{~b}$ ). The abnormal 'bump' at distances $>13 \mathrm{~nm}$ in force curve may be attributed to heterogenous adsorption of $\mathrm{Ca}(\mathrm{OH})^{+}$on silica surface. It is reported that the adsorption capacity (adsorbability) of silica is higher for $\mathrm{Ca}^{\mathrm{II}}$ than $\mathrm{Mg}^{\mathrm{II}}$, correlating with cation bare size and cation solvation energy $^{4}$. Also, the surface potential is related to surface structure ${ }^{2-3}$ which can be slightly different between a silica particle and a silica layer on silicon wafer. Hence, the strong adsorption of $\mathrm{Ca}^{\mathrm{II}}$ may exaggerate the difference in surface potential between the silica layer on the silicon wafer and a silica particle. This explains the larger deviation between fitted surface potential and zeta potentials of silica in $\mathrm{CaCl}_{2}$ condition. Due to the strong $\mathrm{Ca}^{\mathrm{II}}$ adsorption, the silicon wafer is not applicable as a calibration surface in the presence of $\mathrm{Ca}^{\mathrm{II}}$ and trivalent cations even at low electrolyte concentration (e.g. $10 \mathrm{mM})^{4}$. Hence, the surface potential of the silicon 
nitride tip in force fitting is matched to its zeta potential in $10 \mathrm{mM} \mathrm{CaCl}_{2}$, which is retained in the following DLVO fitting for the molybdenite surface.

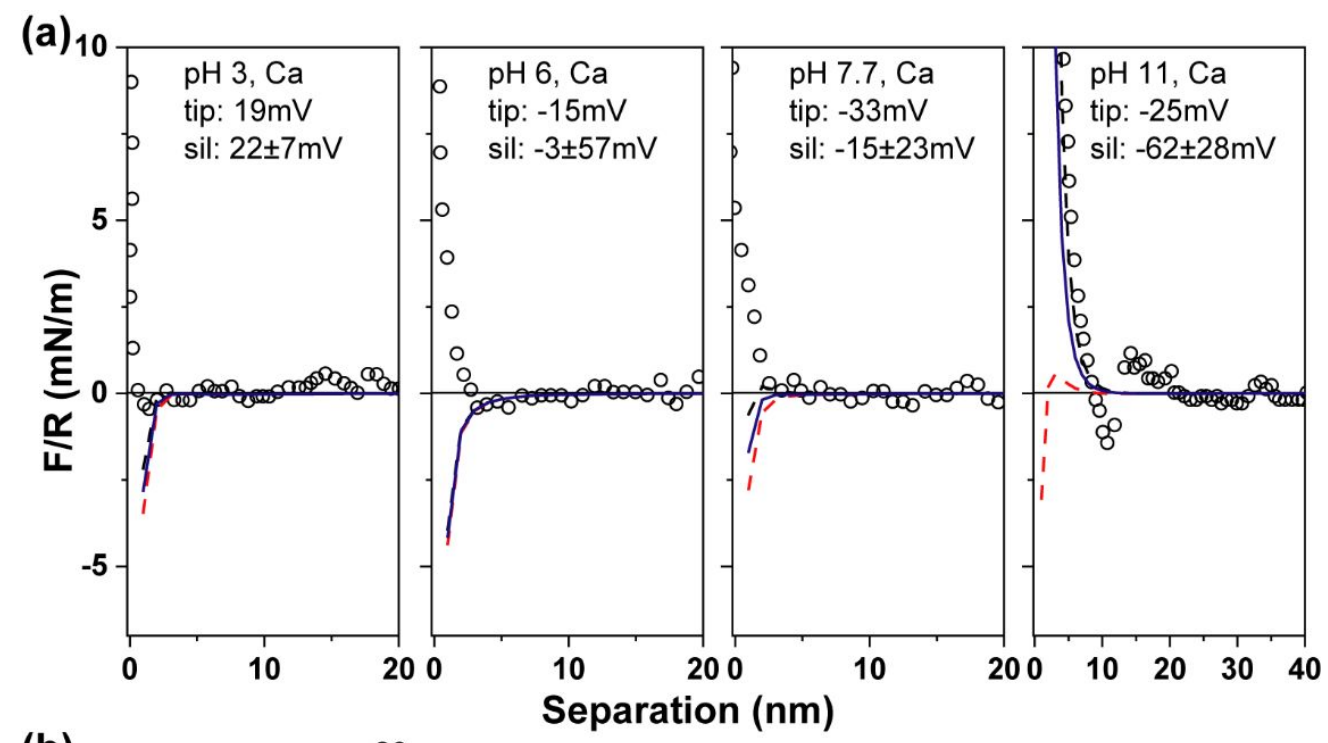

(b)

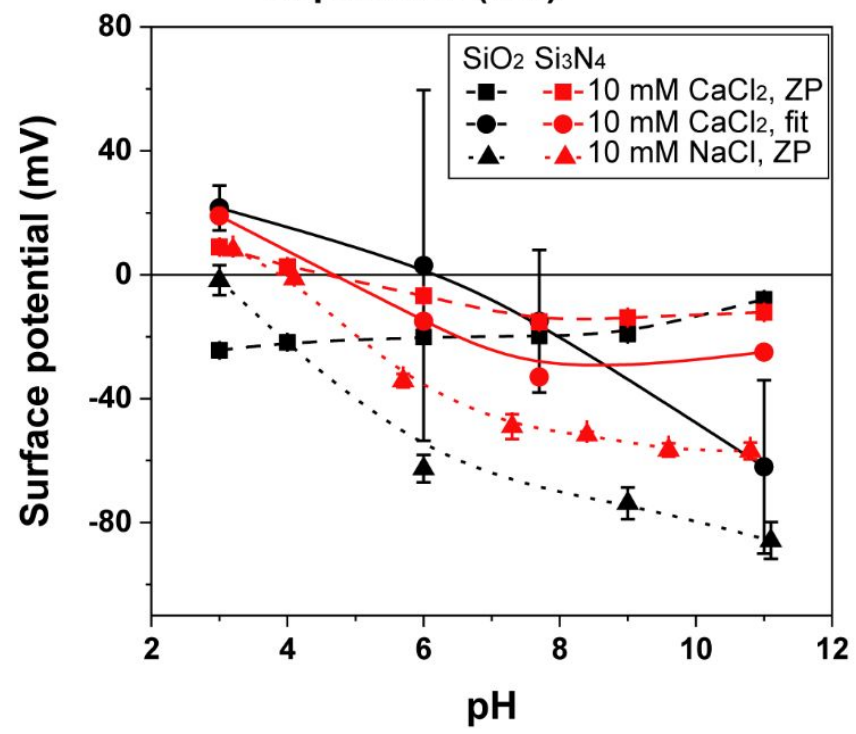

Figure S3. In $10 \mathrm{mM} \mathrm{CaCl}_{2}$, (a) force measurement between silicon nitride tip (tip) and silicon wafer (sil) and DLVO fitting. The symbols represent experimental force curves during approach. The dash and solid lines represent theoretical fittings under constant charge density (black dash), constant potential (red dash) and mixed (blue) boundary conditions. Hamaker constant $A$ is 2.43 
$\times 10^{-20} \mathrm{~J}$ for silicon nitride /aqueous solution/silica system. (b) Surface potential of $\mathrm{SiO}_{2}$ and $\mathrm{Si}_{3} \mathrm{~N}_{4}$ by DLVO force fitting (fit) and zeta potentials (ZP) by electrophoretic measurement.

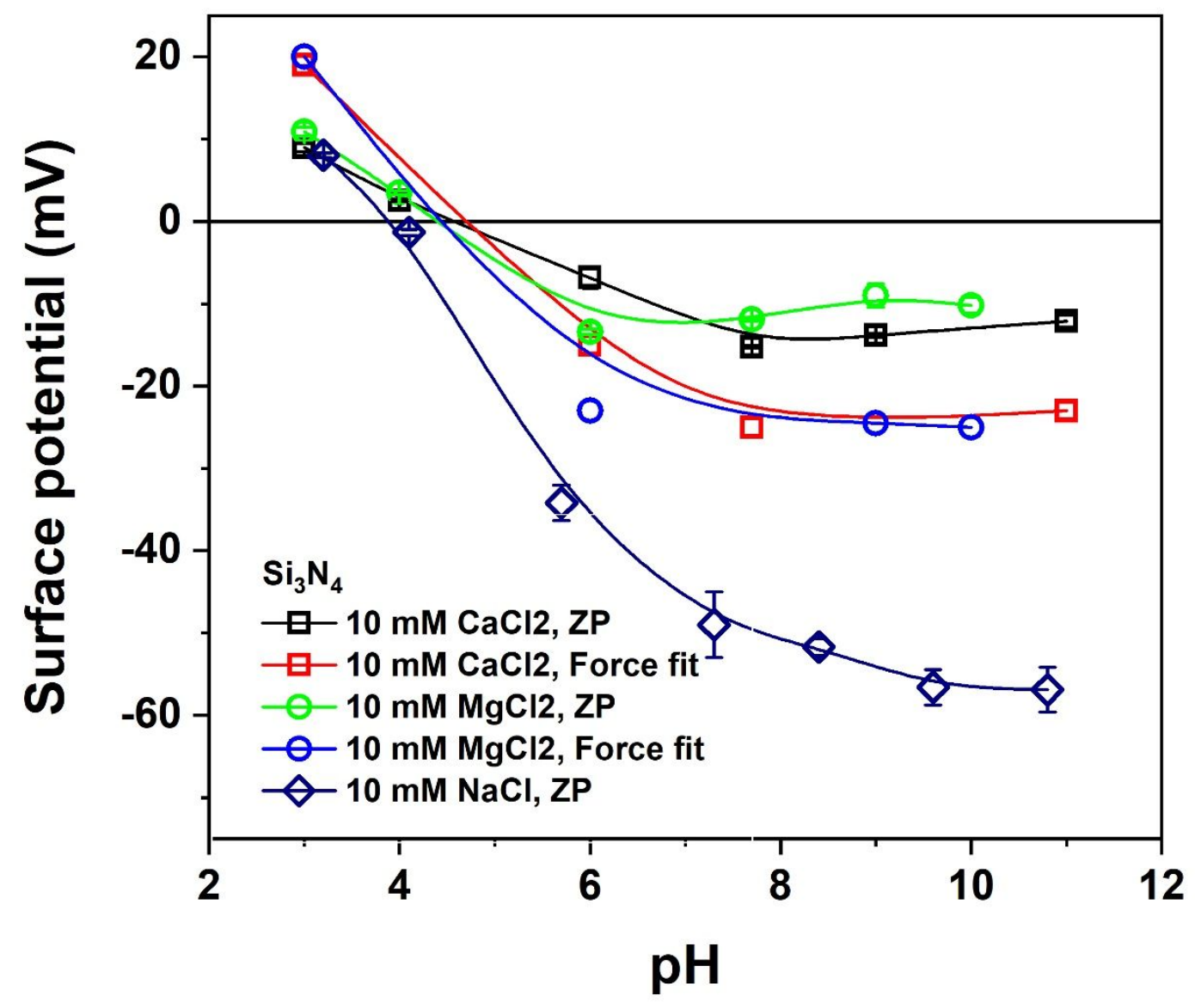

Figure S4. Surface potential of $\mathrm{Si}_{3} \mathrm{~N}_{4}$ in $10 \mathrm{mM} \mathrm{NaCl}, \mathrm{MgCl}_{2}$ and $\mathrm{CaCl}_{2}$ determined by zeta potential measurements (ZP), DLVO force fitting (Force fit). 


\section{REFERENCES}

1. Lu, Z.; Lu, Z.; Peng, S.; Zhang, X.; Liu, Q. Microwetting of Ph-Sensitive Surface and Anisotropic Mos2 Surfaces Revealed by Femtoliter Sessile Droplets. Langmuir 2016, 32, 11273 11279.

2. Li, H. C.; De Bruyn, P. L. Electrokinetic and Adsorption Studies on Quartz. Surface Science 1966, 5, 203-220.

3. Rasmusson, M.; Wall, S. Electrostatic Characterisation of Al-Modified, Nanosized Silica Particles. Colloids and Surfaces A: Physicochemical and Engineering Aspects 1997, 122, 169181.

4. Dishon, M.; Zohar, O.; Sivan, U. Effect of Cation Size and Charge on the Interaction between Silica Surfaces in 1:1, 2:1, and 3:1 Aqueous Electrolytes. Langmuir 2011, 27, 12977 12984. 